\title{
PENGGUNAAN GIONGO DALAM WEBTOON IKEMEN SUGITE
}

\author{
Diana Rizki Oktarina \\ Northern Lights Education Center \\ dianarizkio@gmail.com
}

\begin{abstract}
The aim of this study is to understand the use of one part of the Japanese onomatopoeia, namely giongo consisting of giseigo, a word that shows the sounds of living things, and giongo, a word that shows the sound of inanimate objects, which is found in 15 chapters of Webtoon's Ikemen Sugite (Nayameru Otoko no Nichijyou). By using pragmatic studies, especially in the context of the use of words, it can be seen that the results of this study indicate that there are 10 words included in giseigo, and 10 words included in giongo. The high frequency of using giongo in this webtoon shows that giongo is one type of onomatopoeia that is widely used in language and also a word that represents the emotions of speakers in a written work or conversation so that it is necessary to learn by language learners, including Japanese learners.
\end{abstract}

Keywords: Onomatopoeia, Giongo, Giseigo Vocabulary, Webtoon

\section{Abstrak}

Tujuan penelitian ini adalah untuk mengetahui salah satu bagian dari onomatope Bahasa Jepang, yaitu giongo, yang terdiri dari giseigo, kata yang menunjukkan suara makhluk hidup, dan giongo, kata yang menunjukkan benda mati, yang terdapat dalam 15 chapter Webtoon Ikemen Suite (Nayameru Otoko No Nichijyou). Penelitian ini menggunakan kajian pragmatik, khususnya konteks penggunaan kata, dan berdasarkan analisis yang telah dilakukan terdapat 10 kata giseigo, dan 10 kata giongo. Tingginya frekuensi penggunaan giongo dalam webtoon ini menunjukkan bahwa giongo adalah salah satu onomatope yang banyak digunakan dalam bahasa untuk mewakili emosi penutur dalam karya tulis ataupun percakapan sehingga perlu dipelajari oleh pembelajar bahasa, tidak terkecuali pembelajar bahasa Jepang.

Kata Kunci: Onomatope, Giongo, Giseigo, Kosa kata, Webtoon

\section{PENDAHULUAN}

Onomatope adalah salah satu dari banyaknya kosakata bahasa Jepang. Menurut Maki dan Yuuko, (1) onomatope digunakan untuk menunjukkan emosi dari makna yang disampaikan. Onomatope tidak hanya digunakan dalam bahasa lisan, tapi juga dalam tulisan seperti koran, majalah, novel, dan terutama manga. Seiring perkembangan zaman, berbagai inovasi dalam penggunaan media menjadi lebih praktis dan menarik untuk digunakan, yaitu manga online. Salah satunya adalah suatu aplikasi yang disebut XOY Webtoon. Dalam Webtoon XOY ini, terutama dalam webtoon yang berjudul Ikemen Sugite (Nayameru Otoko ni Nichijyou) ada banyak onomatopoeia Jepang, yang terdiri dari giseigo, giongo, gitaigo, giyougo, dan gijougo. Penelitian ini dilakukan untuk mengetahui penggunaan giongo pada 15 bab 
Ikemen Sugite Webtoon (Nayameru

Otoko no Nichijyou), dengan objek penelitian adalah giongo (giseigo dan giongo) yaitu sebuah kata untuk menunjukkan suara untuk makhluk hidup dan benda mati, yang terdapat dalam chapter tiga, lima, 10, 16, 18, 23, 25, 38, 43, 51, 63, 64, 66, 69, dan 86, karena di dalam beberapa chapter tersebut terdapat giongo dan giseigo yang bervariasi. Kata-kata tersebut akan dianalisis menggunakan salah satu konteks pragmatik, yaitu konteks dari situasi.

Mineko menjelaskan bahwa pragmatik adalah studi yang menganalisis makna kata dan hubungannya dengan konteks dilihat dari berbagai perspektif [2]. Konteks adalah salah satu elemen pragmatik, dan lisan atau tulisan yang sulit dipahami secara tata bahasa, dapat lebih mudah dipahami dengan adanya konteks, seperti yang dijelaskan oleh Suhartono dan Yuniseffendri [3]. Konteks memiliki elemen-elemen yang muncul bersamaan dengan teks, dan elemen-elemen ini adalah pendengar dan pembicara (participant), keadaan atau situasi dan tempat di mana situasi bicara terjadi (setting dan scene), latar belakang (act), makna yang disampaikan oleh pembicara (ends), dan agaimana bahasa disampaikan dalam waktu tertentu (key, instrument, norms and genre). Penelitian ini menganalisis makna suatu kata dengan menggunakan salah satu elemen konteks, yaitu konteks situasi [4]. Keraf menjelaskan bahwa makna adalah aspek isi dari sebuah kata yang menimbulkan reaksi pembaca atau pendengar, atau dengan kata lain memahami kata untuk mengetahui makna, perasaan, nada, dan tujuan kata tersebut. Secara umum, pembagian makna adalah makna denotatif, yang berarti makna dasar dari sebuah kata, dan makna konotatif, yang berarti makna diikuti oleh nilai emosional [5].

Onomatope adalah kata tiruan bahasa Jepang. Walker membaginya menjadi dua jenis yaitu, giongo dan gitaigo, dan masing-masing dibagi lagi menjadi beberapa jenis. Giongo dibagi menjadi giseigo (suara makhluk hidup) dan giongo (suara benda mati). Sementara gitaigo dibagi menjadi gitaigo (keadaan benda mati), giyougo (keadaan atau pergerakan makhluk hidup), dan gijougo (menunjukkan perasaan manusia) [6]. Salah satu jenis onomatope yang difokuskan pada penelitian ini adalah giongo, yang terdiri dari giseigo dan giongo. Berikut adalah contoh kata yang termasuk dalam giseigo and giongo: 
Giongo

ばん 'ban' yang berarti menunjukkan bunyi ledakan

きい ‘kii’ yang berarti menunjukkan bunyi gesekan yang melengking [7]

\section{Giseigo}

アハハ、ハハハ 'ahaha, hahaha'

yang berarti suara tawa

ニャーニャー 'nyaa nyaa' yang berarti suara kucing [8]

Seiring perkembangan zaman, mempelajari kosakata bahasa Jepang seperti giseigo dan giongo, yang telah disebutkan di atas, menjadi lebih mudah. Salah satunya adalah dengan menggunakan aplikasi webtoon yang merupakan penyedia komik digital terbesar di dunia sejak 2004 yang dapat diakses secara gratis [9]. Ada banyak pilihan genre seperti thriller, romantis, slice of life, dan sebagainya. Komik ini dapat dibaca dalam berbagai bahasa seperti Inggris, Indonesia, Thailand, Mandarin pada Line Webtoon, dan yang terbaru adalah dalam versi bahasa Jepang di website XOY Webtoon. Salah satu contohnya adalah komik karya penulis Indonesia yang dapat dibaca dalam versi Jepang dengan judul Ikemen Sugite (Nayameru Otoko no Nichijyou). Webtoon komedi ini menceritakan tentang kehidupan sehari-hari Aren, sebagai tokoh utama, dan keluarganya, termasuk ibunya, memiliki wajah yang sangat tampan yang membuat orang yang melihatnya menjadi kagum atau kaget. Webtoon ini menceritakan kisah komedi yang tidak pernah dibayangkan oleh pembaca.

\section{METODE}

Analisis yang dilakukan dalam penelitian ini sesuai dengan tahapan penelitian yang dijelaskan oleh Muhammad dimulai dengan pengumpulan data, analisis data, dan memperoleh hasil analisis [10]. Data yang dikumpulkan dalam bentuk katakata yang termasuk dalam giseigo dan giongo, yang ditemukan dalam 15 bab dari Webtoon Ikemen Sugite. Analisis data dilakukan dengan melihat maknanya dan akan dijelaskan dengan penggunaannya berdasarkan konteks situasi dalam studi pragmatik. Hasil analisis akan diuraikan dalam bentuk kata giseigo dan giongo dan situasi penggunaan kata-kata ini dalam webtoon.

\section{HASIL DAN PEMBAHASAN}

Terdapat 20 onomatope yang termasuk giseigo dan giongo dalam 
webtoon yang telah dianalisis. Katakata tersebut terdiri dari 10 kata giseigo (ヘヘヘッ,キャー,うわ〜,うぎやっ, ホホホッ,ハッ,ハハッ,フフッ,フッ, dan おんぎゃ〜おんぎゃ〜) dan 10 kata giongo (ウウーン,キーッ, カラ ンカラン, キンコーン, ポトッ, ブォ ーン, ピロンピロン, ピッピッ, コン ッコンッ, dan カチカチッ).

\section{Giseigo}

1. $\sim$

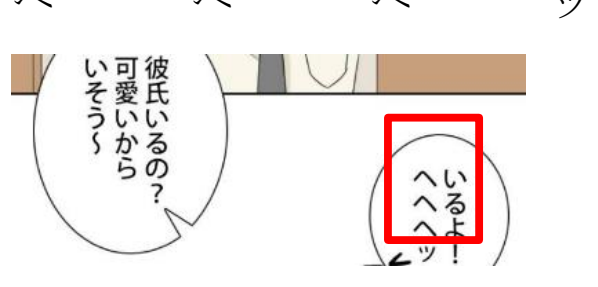

Gambar 1 [11]

Gambar 1 menunjukkan penggunakan giseigo pada chapter 66 Webtoon Ikemen Sugite. Tanda merah menunjukkan giseigo yang berarti tawa seseorang dalam situasi bahagia, karena seseorang yang dia anggap sebagai kekasihnya datang.

2. キャー

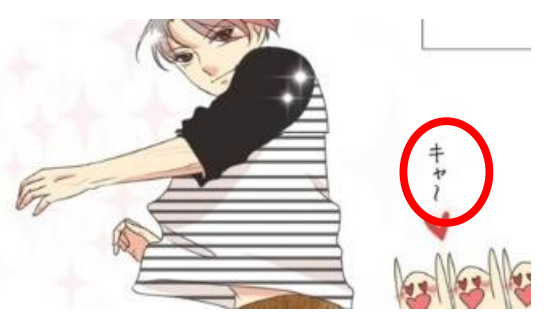

Gambar 2 [11]

Gambar 2 menujukkan penggunaan giseigo pada chapter 10 Webtoon Ikemen Sugite. Tanda merah menunjukkan kata giseigo yang berarti teriakan saat bersorak untuk menunjukkan rasa kagum kepada seseorang.

3. うわ〜

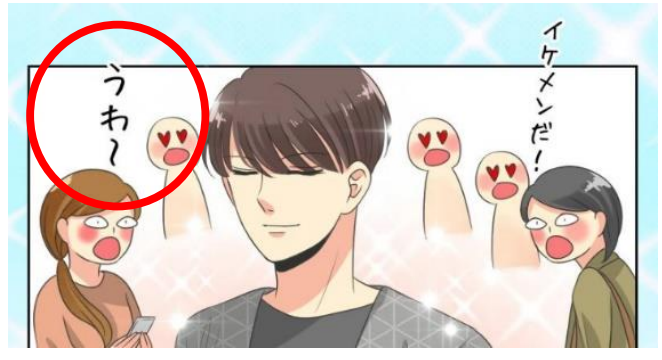

Gambar 3 [11]

Gambar 3 menunjukkan penggunaan giseigo dalam chapter 25 Webtoon Ikemen Sugite. Tanda merah menunjukkan kata giseigo yang berarti suara sorakan ketika terpesona dengan ketampanan seseorang.

4. うぎゃっ

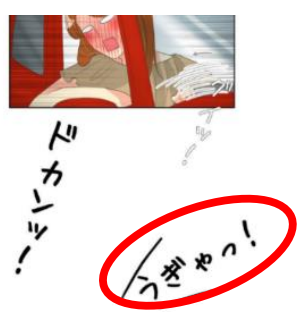

Gambar 4 [11] 


\section{JANARU SAJA}

Jurnal Program Studi Sastra Jepang P-ISSN : 2301-5519 | E-ISSN : 2301-5527

Gambar 4 menunjukkan penggunaan giseigo dalam chapter 16 Webtoon Ikemen Sugite. Tanda merah menunjukkan kata giseigo yang berarti suara teriakan kuat ketika akan menabrak sesuatu.

5. ホホホッ

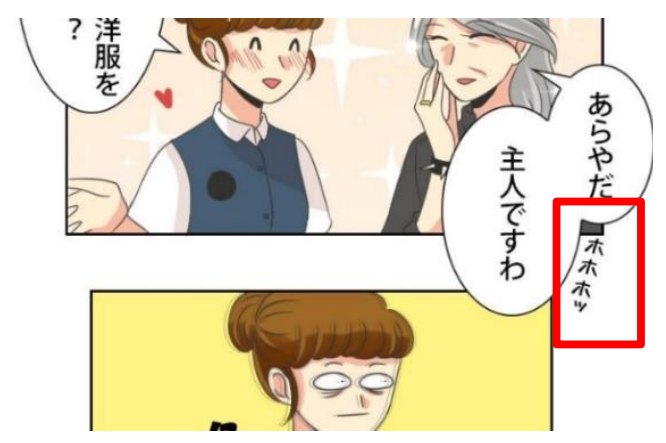

Gambar 5 [11]

Gambar 5 menunjukkan penggunaan giseigo dalam chapter 10 Webtoon Ikemen Sugite. Tanda merah menunjukkan kata giseigo yang berarti suara tawa seseorang yang menutup mulutnya dalam situasi yang menunjukkan kesalahpahaman.

6. ハッ

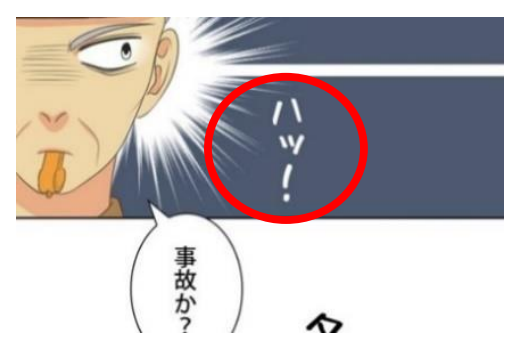

Gambar 6 [11]
Gambar 6 menunjukkan penggunaan giseigo dalam chapter 16 Webtoon Ikemen Sugite. Tanda merah menunjukkan kata giseigo yang berarti suara terkejutnya seseorang yang menyadari terjadinya suatu hal.

7. ハハッ

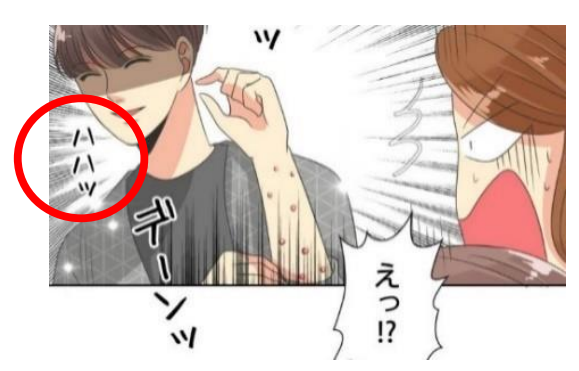

Gambar 7 [11]

Gambar 7 menunjukkan penggunaan giseigo dalam chapter 25 Webtoon Ikemen Sugite. Tanda merah menunjukkan kata giseigo yang berarti suara tawa seseorang ketika hal yang diinginkan menjadi kenyataan.

8. フフッ

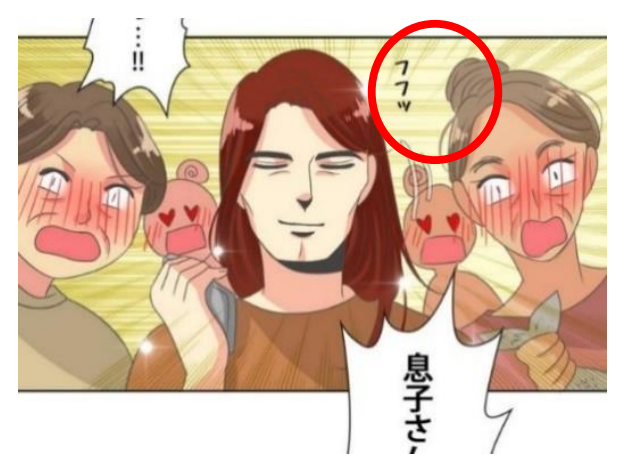

Gambar 8 [11] 


\section{JANARU SAJA}

Jurnal Program Studi Sastra Jepang P-ISSN : 2301-5519 | E-ISSN : 2301-5527

Gambar 8 menunjukkan penggunaan giseigo dalam chapter 23 Webtoon Ikemen Sugite. Tanda merah menunjukkan kata giseigo yang berarti tawa seseorang sambil menghembuskan nafas dalam keadaan senang.

9. フッ

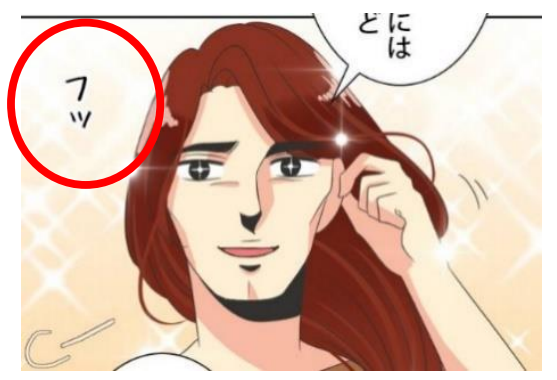

Gambar 9 [11]

Gambar 9 menunjukkan penggunaan giseigo dalam chapter 23 Webtoon Ikemen Sugite. Tanda merah menunjukkan kata giseigo yang berarti tawa seseorang sambil berbangga hati.

10. おんぎや〜おんぎや〜

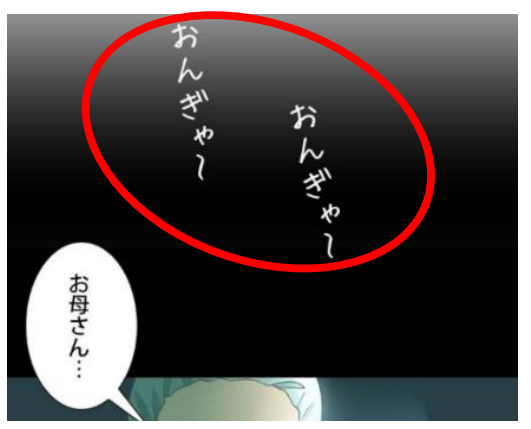

Gambar 10 [11]
Gambar 10 menunjukkan penggunaan giseigo dalam chapter 23 Webtoon Ikemen Sugite. Tanda merah menunjukkan kata giseigo yang berarti suara tangisan bayi pada saat dilahirkan.

\section{Giongo}

1. ウウーン

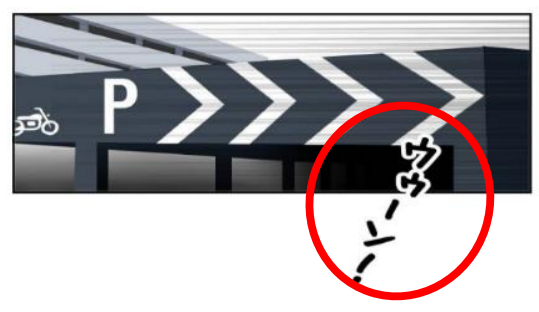

Gambar 11 [11]

Gambar 11 menunjukkan penggunaan giongo dalam chapter 10 Webtoon Ikemen Sugite. Tanda merah menunjukkan kata giongo yang berarti sura erangan motor ketika masuk ke tempat parkir.

2. キーッ

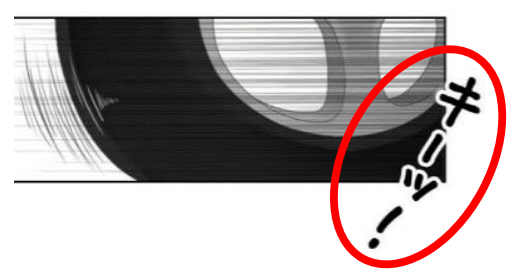

Gambar 12 [11]

Gambar 12 menunjukkan penggunaan giongo dalam chapter 10 Webtoon Ikemen Sugite. Tanda 
merah menunjukkan kata giongo yang berarti suara motor yang direm secara tiba-tiba.

3. カランカラン

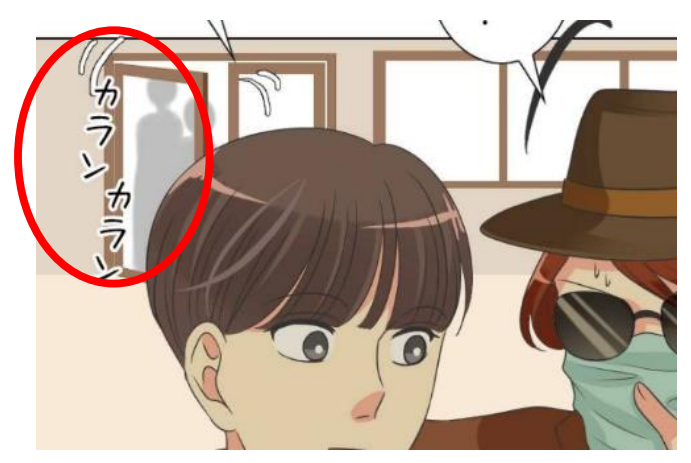

Gambar 13 [11]

Gambar 13 menunjukkan penggunaan giongo dalam chapter 43 Webtoon Ikemen Sugite. Tanda merah menunjukkan kata giongo yang berarti suara bel pintu ketika seseorang membuka pintu.

4. キンコーン

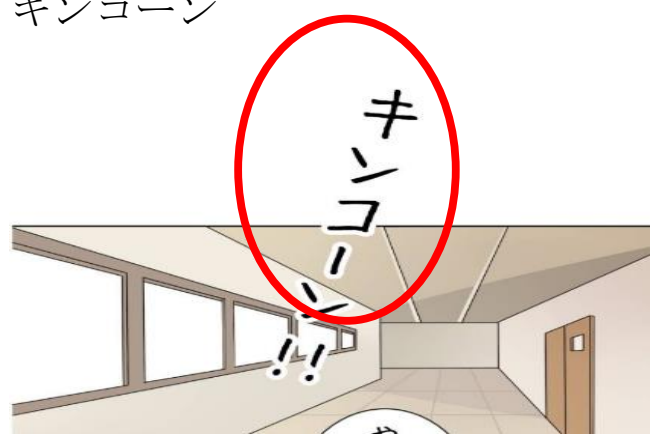

Gambar 14 [11]

Gambar 14 menunjukkan penggunaan giongo dalam chapter 66 Webtoon Ikemen Sugite. Tanda merah menunjukkan kata giongo yang berarti suara bel tanda masuknya sekolah.

5. ポトッ

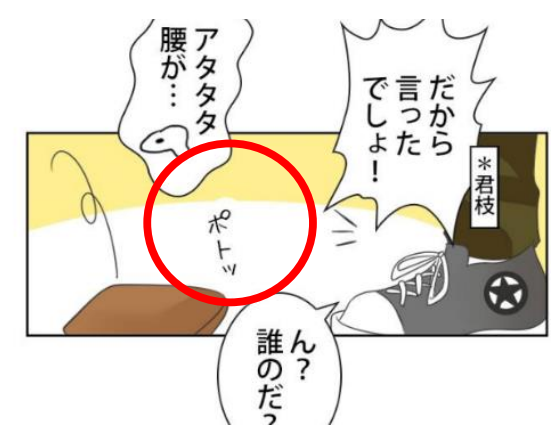

Gambar 15 [11]

Gambar 15 menunjukkan penggunaan giongo dalam chapter 10 Webtoon Ikemen Sugite. Tanda merah menunjukkan kata giongo yang berarti suara benda ringan yang terjatuh.

6. ブォーン

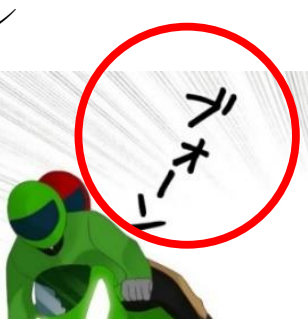

Gambar 16 [11]

Gambar 16 menunjukkan penggunaan giongo dalam chapter 10 Webtoon Ikemen Sugite. Tanda merah menunjukkan kata giongo yang berarti suara motor yang bergerak dengan cepat.

7. ピロンピロン 


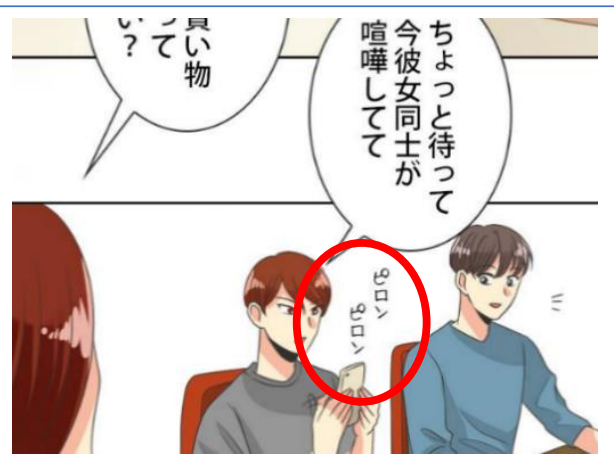

Gambar 17 [11]

Gambar 17 menunjukkan penggunaan giongo dalam chapter 23 Webtoon Ikemen Sugite. Tanda merah menunjukkan kata giongo yang berarti suara telepon genggam ketika ada pesan masuk.

8. ピツピツ

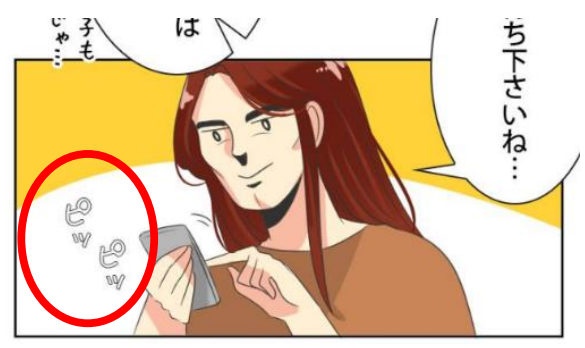

Gambar 18 [11]

Gambar 18 menunjukkan penggunaan giongo dalam chapter 23 Webtoon Ikemen Sugite. Tanda merah menunjukkan kata giongo yang berarti suara tombol telepon genggam ketika akan menelepon.
9. コンッコンッ

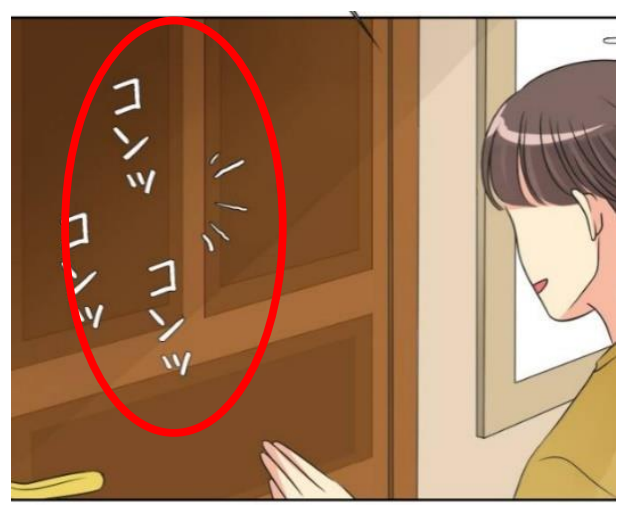

Gambar 19 [11]

Gambar 19 menunjukkan penggunaan giongo dalam chapter 64 Webtoon Ikemen Sugite. Tanda merah menunjukkan kata giongo yang berarti suara ketukan pintu rumah, ketika akan masuk ke rumah seseorang.

10. カチカチッ

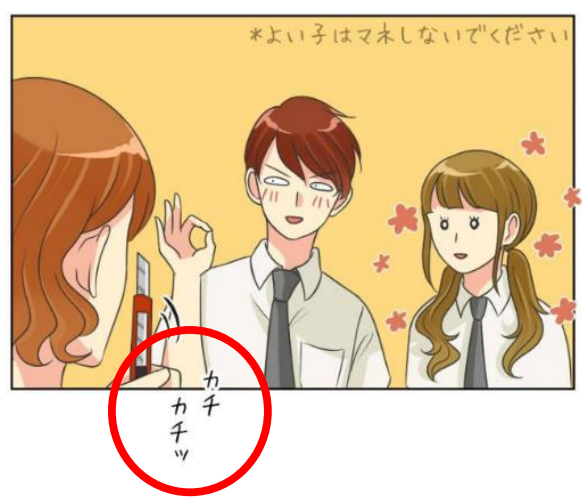

Gambar 20 [11]

Gambar 20 menunjukkan penggunaan giongo dalam chapter 69 Webtoon Ikemen Sugite. Tanda merah menunjukkan kata giongo 
yang berarti suara pemotong kertas yang sedang dibuka.

\section{KESIMPULAN}

Giongo dalam 15 bab webtoon terdiri dari kata-kata yang berhubungan dengan suara tawa (ヘヘヘッ, ホホホ ッ, ハハッ, フフッ, フッ), teriakan (キャー，うわ〜，うぎゃつ，ハッ)， tangisan (おんぎゃ〜おんぎゃ〜), pergerakan (ウウーン, キーッ, ポト ッ,ブオーン, カチカチッ), dan tanpa pergerakan (カランカラン, キンコー ン, ピロンピロン, ピッピッ,コンッ コンッ). Jumlah penggunaan giongo dalam webtoon menunjukkan bahwa giongo adalah salah satu jenis onomatope yang membantu menunjukkan perasaan atau emosi dari yang disampaikan dalam bahasa, termasuk bahasa Jepang, sehingga perlu dipelajari baik secara tertulis maupun lisan. Onomatope tidak hanya terdapat dalam komik online seperri webtoon, tapi juga dalam sumber lainnya, seperti buku, novel, situs web, manga, drama, dan sebagainya. Ada banyak lagi onomatope bahasa Jepang yang digunakan selain giseigo dan giongo, tetapi memiliki jenis lain yang dapat dipelajari oleh pelajar Jepang.

\section{DAFTAR RUJUKAN}

[1] O. Maki and K. Yuko. Nihongo Tango Doriru Giongo Gitaigo, Jepang: ASK. 2007

[2] M. Mineko. Nihongo Goyouronteki Kouzou ni Tsuite. Hokuriku Daigaku Kiyou Dai 27 Gou, September 2003, pp. 91-98. 2003

[3] Suhartono and Yuniseffendri. Pragmatik. In: Pragmatik Selayang Pandang. Universitas Terbuka, Jakarta, pp. 1-37. 2014

[4] D.R. Oktarina, S.M. Setiana, and Renariah. Penggunaan Giyougo dalam Webtoon Ikemen Sugite, Bandung: Universitas Komputer Indonesia. 2018

[5] G. Keraf. Diksi dan Gaya Bahasa, Jakarta: PT Gramedia Pustaka Utama. 2001

[6] I. Walker. Nihongo No Giongo Gitaigo Ni Tsuite No Kenkyuu, Jepang: Hiroshima Daigaku Ryuugaku Sentaa. 2001

[7] H. Fukuda. Jazz Up Your Japanese with Onomatopoeia, 
Jepang: Kodansha International. 2012

[8] A. Satoru. A Practical Guide To Mimetic Through Pictures, Jepang: ALC. 1994

[9] Naver Webtoon Corporation [online]. 2018
[10] Muhammad. Metode Penelitian Bahasa, Yogyakarta: Ar-Ruzz Media. 2011

[11] XOY Webtoon (Japanese). Ikemen Sugite Nayameru Otoko no Nichijyou . [online]. 2017 https://xoy.webtoons.com/ja

[12] Line Webtoon (Indonesian). Terlalu Tampan. [online]. 2017 https://www.webtoons.com/id/ 